\title{
Increased cell death in mouse blastocysts exposed to high D-glucose in vitro: implications of an oxidative stress and alterations in glucose metabolism
}

\author{
A. Leunda-Casi ${ }^{1}$, G. Genicot ${ }^{2}$, I. Donnay ${ }^{2}$, S.Pampfer ${ }^{1}$, R.De Hertogh ${ }^{1}$ \\ ${ }^{1}$ Physiology of Human Reproduction Research Unit, Catholic University of Louvain Medical School, Brussels, Belgium \\ ${ }^{2}$ Veterinary Unit, Catholic University of Louvain, Louvain-la-Neuve, Belgium
}

\begin{abstract}
Aims/hypothesis. Signs of apoptosis have been observed in rodent blastocysts exposed to high D-glucose concentrations in vitro. The mechanism underlying the detrimental influence of glucose remains to be identified. It has been postulated that high D-glucose concentrations induced oxidative stress in rat postimplantation embryos in vitro. A decreased glucose uptake has also been implicated in the embryotoxicity of glucose in pre-implantation mouse embryos. We examined whether the high incidence of cell death in high D-glucose-treated embryos was associated with a disrupted redox status and with alterations in glucose transport and metabolism.

Methods. After blastocysts were incubated in different concentrations of D-glucose for $24 \mathrm{~h}$, they were examined for the proportion of nuclei showing signs of chromatin degradation using the TUNEL technique, for the generation of reactive oxygen species and for the mitochondrial membrane potential using specific fluoroprobes and the confocal microscopy.
\end{abstract}

Received: 24 August 2001 and in revised form: 30 October 2001

Corresponding author: R. De Hertogh MD, PhD, OBST 5330 Research Unit, Catholic University of Louvain Medical School, 53 Avenue E. Mounier, 1200 Brussels, Belgium, email: dehertogh@ obst.ucl.ac.be

Abbreviations: ICM, Inner cell mass; TE, trophectoderm; TUNEL, terminal deoxynucleotidyl transferase-mediated dUTP nick end labelling; ROS, reactive oxygen species; DCHFDA, dichlorodihydrofluorescein-diacetate molecule; JC-1, tetrachloro-tetraethyl benzimidazolylcarbocyanine
Glucose transport and metabolism were assessed using radiolabelled 3-O-methylglucose and glucose, respectively.

Results. Compared to the control blastocysts, high Dglucose-treated embryos showed a higher incidence of TUNEL-positive nuclei and reactive oxygen species generation principally in the inner cell mass cells. Decreased glucose transport and glycolytic activity but unmodified pentose phosphate pathway activity were detected in these embryos.

Conclusion/interpretation. Incubation in high D-glucose concentrations in vitro increased cell death, induced oxidative stress and decreased glucose transport and metabolism in mouse blastocysts. As only glycolysis was affected, however, we suggest that metabolic inhibition occurred downstream glucose transport and glucose-6-phosphate formation. [Diabetologia (2002) 45:571-579]

Keywords Blastocyst, apoptosis, oxidative stress, glucose uptake, glucose metabolism.
Pregnancy in a diabetic mother involves a higher risk of early foetal loss and congenital malformations [1, $2,3]$. In addition to extensive studies on the deleterious effect of maternal diabetes on early fetal organogenesis, several observations in rats and mice have shown that embryo growth is already impaired at the pre-implantation stage of development $[4,5,6]$.

Pre-implantation mouse embryos reach the blastocyst stage 4 days after fertilisation and shortly before their engagement in the process of implantation into the uterine wall. Two distinct cell lineages, the trophectoderm (TE) and the inner cell mass (ICM) are already present at this stage of development. The pe- 
ripheral TE consists of a single layer of epithelioid cells that is bound to differentiate into trophoblasts and to contribute to the formation of the placenta. The ICM, in contrast, is an inner cluster of totipotent stem cells that continue to diversify into a variety of cell types to generate the different foetal tissues and organs during organogenesis. Numerous studies have shown that ICM and TE cells diverge in many cellular, biochemical and molecular aspects, including their susceptibility to embryotoxic agents [7].

Data reported in rats and mice support the hypothesis that factors in the diabetic uterine milieu or hyperglycaemia in vitro increases the incidence of different apoptotic markers in the blastocyst stage embryo. Blastocysts recovered from diabetic rats had higher incidences of nuclear fragmentation and chromatin degradation and higher levels of clusterin transcripts than the control embryos [8]. Dead cells were mainly observed in the ICM cell lineage $[9,8]$. Blastocysts recovered from diabetic mice had higher mRNA and protein expression of the pro-apoptotic Bax effector [10]. These increased incidences in apoptotic markers were also observed in vitro after high D-glucose was added to the culture medium of mouse or rat blastocysts from normal female, suggesting that glucose adds to the induction of apoptosis $[8,10]$.

The mechanism of the detrimental influence of glucose on the development of peri-implantation embryos has yet to be identified. It has been postulated that excess oxygen free radicals are produced in the diabetic state and cause diabetes-induced malformations in post-implantation rat embryos [11, 12]. This hypothesis is supported by evidence showing that free oxygen radicals scavenging enzymes and antioxidant compounds protect against glucose-induced malformations in these embryos. Such a mechanism involving reactive oxygen species (ROS) and the loss of cell viability might also function in peri-implantation embryos exposed to maternal diabetes or high D-glucose concentrations in vitro.

It has also been proposed that high D-glucose-exposed blastocysts could engage in apoptosis in response to glucose uptake deficiency. This assertion is based on experiments showing that high D-glucose concentrations caused a sharp decline in the expression of several glucose transporters in rat trophoblastic cell lines [13] and in mouse blastocysts [14]. In these conditions, down-regulation of facilitative glucose transporters was accompanied by a decrease in their glucose uptake. This response could lead to insufficient intra-embryonic levels of glucose to support their metabolic requirements and ultimately trigger cell suicide.

We examined whether the incidence of cell death and the redox status of the embryos were modified in mouse blastocysts when exposed to high concentrations of D-glucose for 24 hours in vitro. Alterations in glucose transport and metabolism were also investigated under the same conditions.

\section{Materials and methods}

Embryo collection and culture. All investigations were carried out in accordance with the "Guide for Care and Use of Laboratory Animals" (National Academy of Science, 1996). Sixweek-old female mice from the NMRI strain (University Animal House, Brussels, Belgium) were mated overnight with B6D2F1 strain male mice (Iffa Credo, L'Arbresle, France). The presence of a vaginal plug was designated as day 1 of pregnancy. Early blastocysts were recovered on day 4 by flushing the uterine horns with pre-warmed Earle's balanced salt solution (EBSS, Life Technologies, Parsley, UK) culture medium supplemented with $1 \mathrm{mmol} / \mathrm{l}$ glutamate, $1 \mathrm{mmol} / 1$ pyruvic acid, $0.3 \%$ BSA, $100 \mathrm{U} / \mathrm{ml}$ penicillin and $100 \mu \mathrm{g} / \mathrm{ml}$ streptomycin. Blastocysts were analysed after a $24 \mathrm{~h}$ culture period at $37^{\circ} \mathrm{C}$ in the culture medium supplemented with either $6 \mathrm{mmol} / \mathrm{l}$ D-glucose $(6 \mathrm{mmol} / \mathrm{l}$ D-G), $28 \mathrm{mmol} / \mathrm{l}$ D-glucose $(28 \mathrm{mmol} / \mathrm{l} \mathrm{D}-\mathrm{G})$ or a combination of $6 \mathrm{mmol} / \mathrm{l} \mathrm{D}$-glucose and $22 \mathrm{mmol} / \mathrm{l} \mathrm{L}$-glucose $(6+22 \mathrm{mmol} / \mathrm{l} \mathrm{D}+\mathrm{L}-\mathrm{G})$.

Detection of chromatin degradation. The incidence of chromatin degradation was analysed with the TUNEL method and with bisbenzimide-staining (HO-staining) [8]. Zona pellucidafreed blastocysts were fixed in $4 \%$ paraformaldehyde in PBS, exposed to $0.3 \%$ hydrogen peroxide in methanol and permeabilized in $0.1 \%$ Triton X-100 in $0.1 \%$ sodium citrate. Blastocysts were then pre-stained in $10 \mu \mathrm{g} / \mathrm{ml}$ of bisbenzimide. After the embryos were rinsed in PBS, they were incubated with 50 $\mathrm{U} / \mathrm{ml}$ of terminal deoxynucleotidyl transferase and $15 \mu \mathrm{mol} / \mathrm{l}$ of fluorescein-deoxyuridine 5-triphosphate (dUTP; Roche Diagnostics-Boehringer, Mannheim, Germany), and then exposed to a sheep anti-fluorescein antibody conjugated with peroxidase. TUNEL-staining was developed in a solution of diaminobenzidine and nickel chloride. Index of cells with TUNEL-positive chromatin degradation was expressed in individual blastocysts as the percentage of the total number of cells counted per blastocyst. Three to six independent experiments were done and about 30 blastocysts analysed in each experimental group.

Detection of ROS. The dichlorodihydrofluorescein diacetate molecule (DCHFDA, Molecular Probe, Leiden, The Netherlands) was used to determine the quantity of ROS produced by the embryos. Briefly, the principle of the procedure is that: non-ionised DCHFDA is membrane-permeant and diffuses into cells. The acetate groups were released in the cell by intracellular esterase activity forming the dichlorodihydrofluorescein $(\mathrm{DCHF})$ which is polar and trapped within the cell. The DCHF molecule fluoresces when it is oxidized and yields dichlorofluorescein (DCF). The DCF concentration produced linearly relates to that of ROS [15]. DCHFDA was prepared as a $1 \mathrm{mg} / \mathrm{ml}$ stock solution in DMSO and blastocysts were incubated in the culture medium containing $10 \mu \mathrm{mol} / \mathrm{l}$ DCHFDA during $1 \mathrm{~h} 30 \mathrm{~min}$ at $37^{\circ} \mathrm{C}$. They were washed in PBS and observed with a Bio-Rad MRC 1024 confocal laser scanning system microscope (Zeiss, Germany). Stacks of digital sections were acquired along the Z-axis (Z-series) at an interval of $5 \mu \mathrm{m}$ throughout the pre-implantation embryo. Whole embryos were reconstituted onto a single image by a vertical projection of $\mathrm{Z}$-series. The peroxides in the pre-implantation blastocysts were estimated by measuring the average intensity signal of each section that had been acquired 
across the embryo using the Scion-modified NIH Image program (version 1.62). Quantification was corrected for variations in corresponding background and section areas. Results are expressed as the percentage of total fluorescence emitted by blastocysts treated with $0.5 \mathrm{mmol} / \mathrm{l} \mathrm{AAPH}$ for $4 \mathrm{~h}\left[2,2^{\prime}-\mathrm{Az}-\right.$ obis(2-aminopropane) dihydrochloride, Interchim, Montluçon, France]. This oxidant agent is known to initiate oxidation of lipids and proteins $[16,17]$. The average intensity signal emitted by the fluorescent marker in blastocysts exposed to AAPH has been shown to increase by 4.5 -fold compared with control blastocysts (data not shown). Similar results were obtained with the tert-butyl hydroperoxide or hydrogen peroxide as oxidant agents. A semi-quantitative estimation of ROS in the ICM and TE lineages was carried out in the blastocysts exposed to $28 \mathrm{mmol} / \mathrm{l} \mathrm{D}$-glucose. Three sections per blastocyst acquired in the equatorial region of the embryo were measured for the mean intensity signal in the ICM and TE regions. About 10 blastocysts were analysed for each group in three separate experiments.

Assessment of mitochondrial changes. Mitochondrial membrane potential was analysed in blastocysts using the fluorochrome JC-1 (Molecular Probes, Leiden, The Netherlands), a cationic dye which incorporates into mitochondria and exists as a monomer at low membrane potential (green fluorescence) or as aggregates at high membrane potential (red fluorescence). Mitochondrial depolarization is indicated by a decrease in the red-to-green intensity ratio. JC-1 was prepared as a $1 \mathrm{mg} / \mathrm{ml}$ stock solution in DMSO and blastocysts were incubated $15 \mathrm{~min}$ in a $5 \mathrm{\mu g} / \mathrm{ml}$ solution in culture medium. They were washed before their examination with a laser scanning confocal microscope. Images were recorded and analysed as described above. About ten blastocysts were analysed for each group in three separate experiments.

Glucose transport. Glucose transport was measured in embryos using the initial rate of uptake of 3-o-methyl-D-[1- $\left.{ }^{3} \mathrm{H}\right] \mathrm{glu}-$ cose, a non-metabolised analogue of glucose $\left(\left[{ }^{3} \mathrm{H}\right] 3-\mathrm{OMG}\right.$, $233 \mathrm{GBq} / \mathrm{mmole}$, Amersham Pharmacia Biotech, Buckinghamshire, England) over $3 \mathrm{~min}$ at $37^{\circ} \mathrm{C}$ in $10 \mu \mathrm{l}$ droplets of glucose-free EBSS medium containing $0.3 \mathrm{mmol} / 1\left[{ }^{3} \mathrm{H}\right] 3-\mathrm{OMG}$ and $25 \mathrm{mmol} / \mathrm{l}$ 3-OMG (Sigma, St Louis, Mo., USA) [18]. Transferring the embryos through four washes of ice-cold glucose-free EBSS stopped uptake. Then, five to ten embryos were placed in a plastic mini-vial to which $200 \mu$ l of water and $3 \mathrm{ml}$ of scintillation liquid were added. Radioactivity was measured during $10 \mathrm{~min}$ in each vial (Tri-Carb 4000, Packard). A correction was made for radioactivity measured in $2 \mu \mathrm{l}$ of the last wash medium. Four independent experiments were carried out resulting in about 50 blastocysts analysed in each group.

Metabolic studies. In these experiments, $\left[5-{ }^{3} \mathrm{H}\right]$, $\left[\mathrm{U}-{ }^{14} \mathrm{C}\right]$, or $[6-$ $\left.{ }^{14} \mathrm{C}\right]$ glucose were used to evaluate the main glucose metabolic pathways in blastocysts [19-22]. $\left[6-{ }^{14} \mathrm{C}\right]$ glucose $(2.07 \mathrm{GBq} /$ mmole; Amersham, UK) was used to measure glucose oxidation through the Krebs cycle, on the basis of a one-to-one molar ratio between ${ }^{14} \mathrm{CO}_{2}$ recovered and $\left[6-{ }^{14} \mathrm{C}\right]$ glucose oxidized. [U- ${ }^{14} \mathrm{C}$ ] glucose (11.5 GBq/mmole; Amersham, UK) served to estimate total glucose oxidation by the Krebs cycle and the pentose phosphate pathway (PPP). Finally, $\left[5-{ }^{3} \mathrm{H}\right] \mathrm{glu}-$ cose $(518 \mathrm{GBq} / \mathrm{mmole}$; Amersham, UK) was used to measure the glycolytic pathway, assuming a one-to-one molar ratio between ${ }^{3} \mathrm{H}_{2} \mathrm{O}$ produced and $\left[5-{ }^{3} \mathrm{H}\right]$ glucose metabolised.

After the incubation in the different concentrations of glucose for $24 \mathrm{~h}$, the embryos were suspended in a $5 \mu \mathrm{l}$ microdrop of culture medium containing HEPES ( $25 \mathrm{mmol} / \mathrm{l})$ and radio- labelled glucose at a final concentration of $0.28 \mathrm{mmol} / \mathrm{l}$. This glucose concentration is close to that saturating glucose uptake in mice [21] and in rats [22]. The microdrop laying on the inside surface of a cap, was gently fixed on top of the corresponding $1.5 \mathrm{ml}$ tube which contained $1 \mathrm{ml} 0.1 \mathrm{~mol} / \mathrm{l} \mathrm{NaOH}$. The tubes were incubated at $37^{\circ} \mathrm{C}$ for $4 \mathrm{~h}$. Then, the $\mathrm{NaOH}$ was quantitatively transferred to a counting vial containing $14 \mathrm{ml}$ of scintillation mixture (Instagel, Packard Instrument, Groningen, The Netherlands) and radioactivity was measured (Tri-Carb 4000, Packard). A correction was made for radioactivity measured in a blank metabolic chamber containing the same metabolic substrate but no embryo in the suspended microdrop. Three to six experiments were done resulting in a total of more than 20 blastocysts analysed per metabolic pathway and in each group.

Statistical analysis. The results in the graphs are given as means \pm SEM values. One-way analysis of variance coupled to posthoc Fisher's test was used to determine the significance of differences between the groups in all experiments. This test was done for fluorescence intensity quantification (ROS and mitochondrial membrane potentials) after a two-way ANOVA analysis to confirm the absence of a significant interaction between the replicate and the treatment. Statistical significance was reached at a $p$ value of less than 0.05 .

\section{Results}

Increased incidence of cell death in blastocyst exposed to high $\mathrm{D}-$ glucose. Mouse blastocysts were incubated for $24 \mathrm{~h}$ in either $6 \mathrm{mmol} / \mathrm{l}$ or $28 \mathrm{mmol} / \mathrm{l} \mathrm{D}$-glucose and analysed to detect cells showing signs of chromatin degradation (Fig.1). No difference in the cell number was observed between the experimental groups ( $p=0.866$, Fig. $1 \mathrm{~A})$ but the TUNEL-positive cell index was increased by $30 \%$ in blastocysts exposed to high D-glucose compared to that of the control embryos ( $p \leq 0.05$, Fig. 1B). The ICM region accounted for $83 \%$ of total TUNEL-positive cells (data not shown). None of the parameters analysed above were modified when blastocysts were cultured in a combination of $6 \mathrm{mmol} / \mathrm{l}$ D-glucose and $22 \mathrm{mmol} / \mathrm{l} \mathrm{L}$-glucose.

ROS detection in blastocysts incubated in high $\mathrm{D}-$ glucose. Mouse blastocysts incubated for $24 \mathrm{~h}$ in different glucose concentrations and loaded with DCHFDA were observed by confocal microscopy (Fig.2). Thereby, control blastocysts incubated in $6 \mathrm{mmol} / \mathrm{l} \mathrm{D-glucose}$ showed a weak and diffuse cellular fluorescence (Fig. 2A). An increased fluorescent signal was observed in the ICM region of embryos exposed to high D-glucose for $24 \mathrm{~h}$ (Fig. 2B). In addition, some of these embryos presented a signal similar to that detected in the embryos treated with the oxidant agent AAPH dispersed fluorescence in their blastocoelic cavity (Fig. 2C). The relative fluorescent signal in blastocysts exposed to high D-glucose showed a 2.8fold increase compared to that of control blastocysts $(p \leq 0.05$, Fig. $2 \mathrm{G})$. When the signal intensities in 


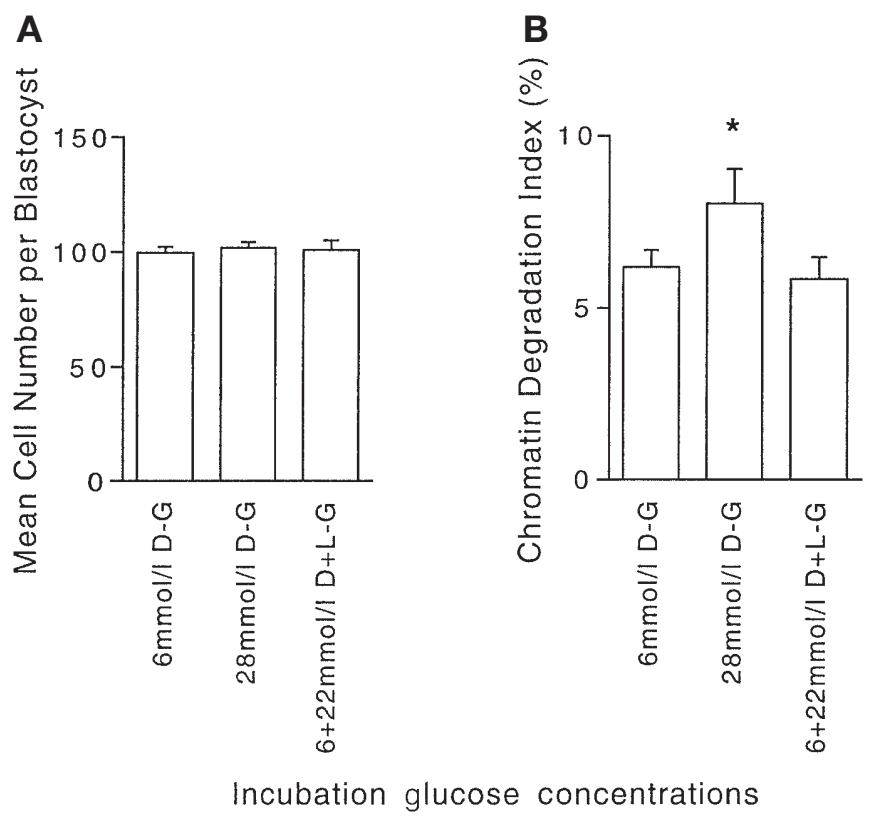

Fig.1. Influence of an exposure to different concentrations of glucose during $24 \mathrm{~h}$ on mouse blastocysts development $(n=22-46)$. A Average number of cells and $\mathbf{B}$ chromatin degradation index per blastocyst. $* p \leq 0.05$

ICM and TE regions were estimated in sections acquired across blastocysts exposed to $28 \mathrm{mmol} / \mathrm{l} \mathrm{D-glu-}$ cose, there was a 1.8-fold higher absolute value in the ICM core than in the TE region $(p \leq 0,05$; data not shown). Blastocysts exposed to the $6 \mathrm{mmol} / \mathrm{l} \mathrm{D-glu-}$ cose and $22 \mathrm{mmol} / \mathrm{l} \mathrm{L}$-glucose combination presented a similar signal to that emitted by the control blastocysts.

Mitochondrial membrane potential changes in blastocysts exposed to high D-glucose. Mouse blastocysts incubated for $24 \mathrm{~h}$ in $6 \mathrm{mmol} / \mathrm{l}$ or $28 \mathrm{mmol} / \mathrm{l} \mathrm{D}$-glucose loaded with JC-1 and observed by confocal microscopy (Fig. 3) showed a large number of high potential membrane mitochondria. In contrast a limited number of low potential mitochondria was homogeneously distributed in the cytoplasm of TE cells with a more dense peri-nuclear accumulation (Fig. 3A-B). The ICM cells failed to stain. No variations in mitochondrial membrane potentials were detected between the experimental groups after quantitative estimation ( $p=0.509$, Fig. 3D).

Glucose transport and metabolism in blastocysts treated with high $\mathrm{D}$-glucose. After incubation in $6 \mathrm{mmol} / \mathrm{l}$ or $28 \mathrm{mmol} / \mathrm{l} \mathrm{D}$-glucose for $24 \mathrm{~h}$, blastocysts were analysed for glucose uptake and the main glucose metabolic pathways (Fig. 4). The initial rate of 3-OMG uptake by blastocysts was decreased by threefold after $24 \mathrm{~h}$ of incubation in high concentrations of glucose compared to that of the control embryos $(p \leq 0.05$, Fig. 4A). The overall glucose utilization through glyc- olysis was reduced by $28 \%$ in blastocysts incubated in high D-glucose compared to the control embryos ( $p \leq 0.01$, Fig. 4B). The ${ }^{14} \mathrm{CO}_{2}$ produced from $\left[6-{ }^{14} \mathrm{C}\right]$ glucose, a value used to analyse the activity of the Krebs cycle, was slightly decreased in the high D-glucose group ( $p=0.067$, Fig. $4 \mathrm{C})$. Total glucose oxidation, measured as the ${ }^{14} \mathrm{CO}_{2}$ produced from $\left[\mathrm{U}-{ }^{14} \mathrm{C}\right]$ glucose metabolism, was not modified by the exposure to high D-glucose concentrations for $24 \mathrm{~h}(p=0.109$, Fig. 4D). Considering that $\left[\mathrm{U}^{-14} \mathrm{C}\right]$ glucose yields six times more ${ }^{14} \mathrm{CO}_{2}$ per mole than $\left[6^{-14} \mathrm{C}\right]$ glucose via complete oxidation in the Krebs Cycle and that the ${ }^{14} \mathrm{CO}_{2}$ was released from oxidation of $\left[6-{ }^{14} \mathrm{C}\right]$ glucose through the Krebs Cycle only, it could be calculated that $85 \%$ and $91 \%$ of the ${ }^{14} \mathrm{CO}_{2}$ recovered from oxidation of $\left[\mathrm{U}^{1}{ }^{14} \mathrm{C}\right]$ glucose were released principally by the PPP in blastocysts exposed to $6 \mathrm{mmol} / \mathrm{l}$ and $28 \mathrm{mmol} / \mathrm{l} \mathrm{D}$-glucose respectively. The different metabolic parameters analysed above were not modified when blastocysts were cultured $24 \mathrm{~h}$ in a combination of $6 \mathrm{mmol} / \mathrm{l} \mathrm{D}$-glucose and $22 \mathrm{mmol} / \mathrm{l} \mathrm{L}$-glucose.

\section{Discussion}

Our data showed an increased incidence of cells showing signs of nuclear chromatin degradation, particularly in the ICM cell lineage of mouse blastocysts exposed to high D-glucose concentrations for $24 \mathrm{~h}$. Recent studies have shown the expression of different pro-apoptotic and anti-apoptotic effectors and their implication in high glucose-induced apoptosis in rodent blastocysts. A higher proportion of cells showed anti-apoptotic $\mathrm{Bcl}-2$ gene transcription and protein expression in rat blastocysts exposed to high D-glucose compared to control embryos [23]. In similar culture conditions, specific inhibition of caspase-3 or caspase-activated deoxyribonuclease (CAD) activities in rat blastocysts prevented high glucose-induced apoptosis [24]. Bcl-2, caspase-3 and CAD have been shown to participate in the intracellular cascade leading to high glucose-induced chromatin degradation in rat blastocysts. An increased incidence of apoptotic cells has also been associated with the activation of caspase-1, the generation of ceramide and with increased expressions of the proapoptotic Bax mRNA and protein in mouse blastocysts after exposure to high glucose concentrations in vitro [10].

Our study showed an increased presence of ROS in blastocysts exposed $24 \mathrm{~h}$ to high D-glucose concentrations compared to the control embryos. Cells showing highly fluorescent points were mainly localized in the ICM region, whereas the TE cells rarely emitted a signal. Some experiments on blastocysts recovered from another female mouse strain (OF1) showed a similar pattern of fluorescence to that of embryos recovered from the NMRI female strain 

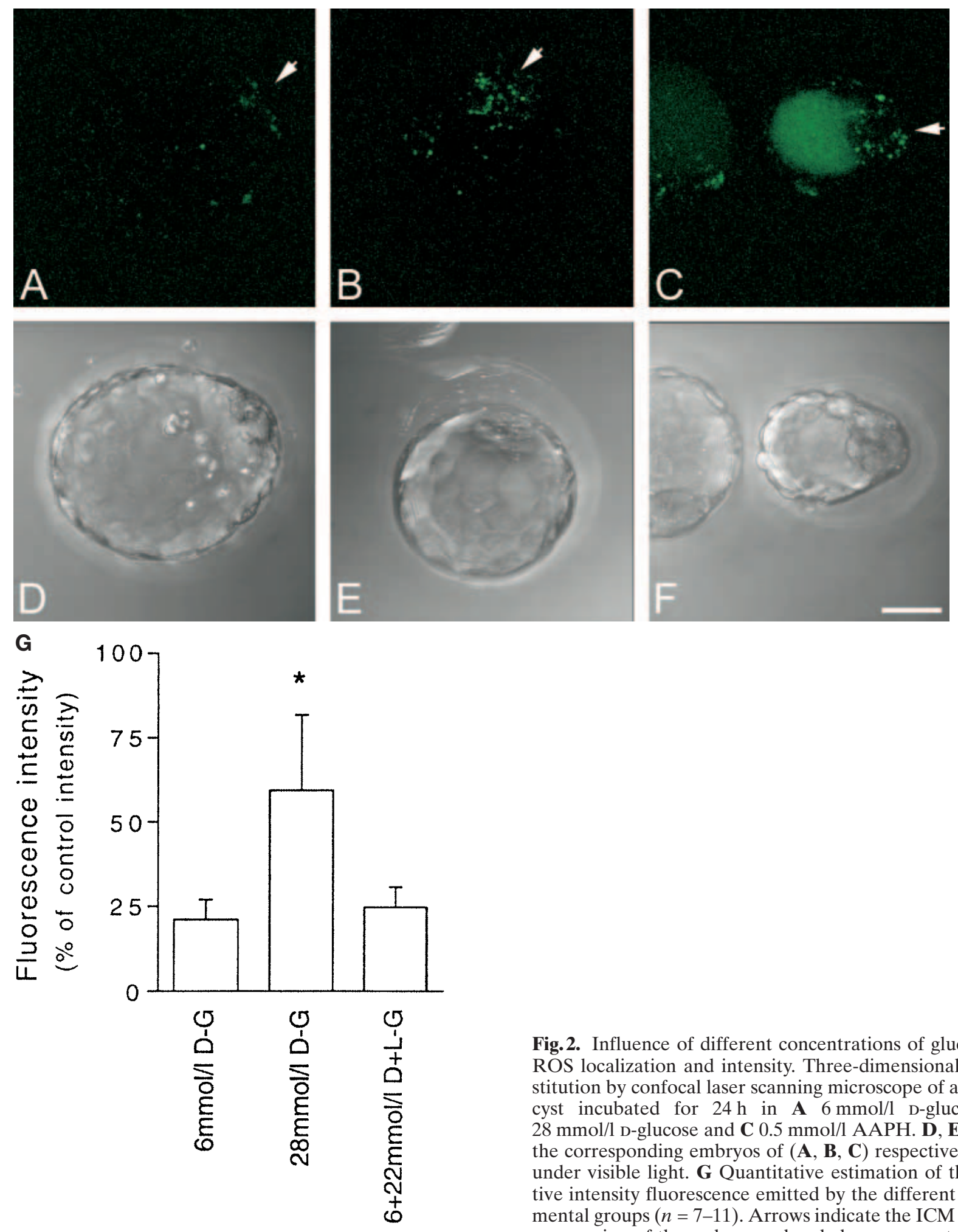

Incubation glucose concentrations

Fig. 2. Influence of different concentrations of glucose on ROS localization and intensity. Three-dimensional reconstitution by confocal laser scanning microscope of a blastocyst incubated for $24 \mathrm{~h}$ in A $6 \mathrm{mmol} / \mathrm{l}$ D-glucose, B $28 \mathrm{mmol} / \mathrm{l}$ D-glucose and C $0.5 \mathrm{mmol} / \mathrm{l} \mathrm{AAPH}$. D, E, F Are the corresponding embryos of $(\mathbf{A}, \mathbf{B}, \mathbf{C})$ respectively, seen under visible light. G Quantitative estimation of the relative intensity fluorescence emitted by the different experimental groups $(n=7-11)$. Arrows indicate the ICM cell lineage region of the embryo and scale bar represents $30 \mu \mathrm{m}$. $* p \leq 0.05$ 

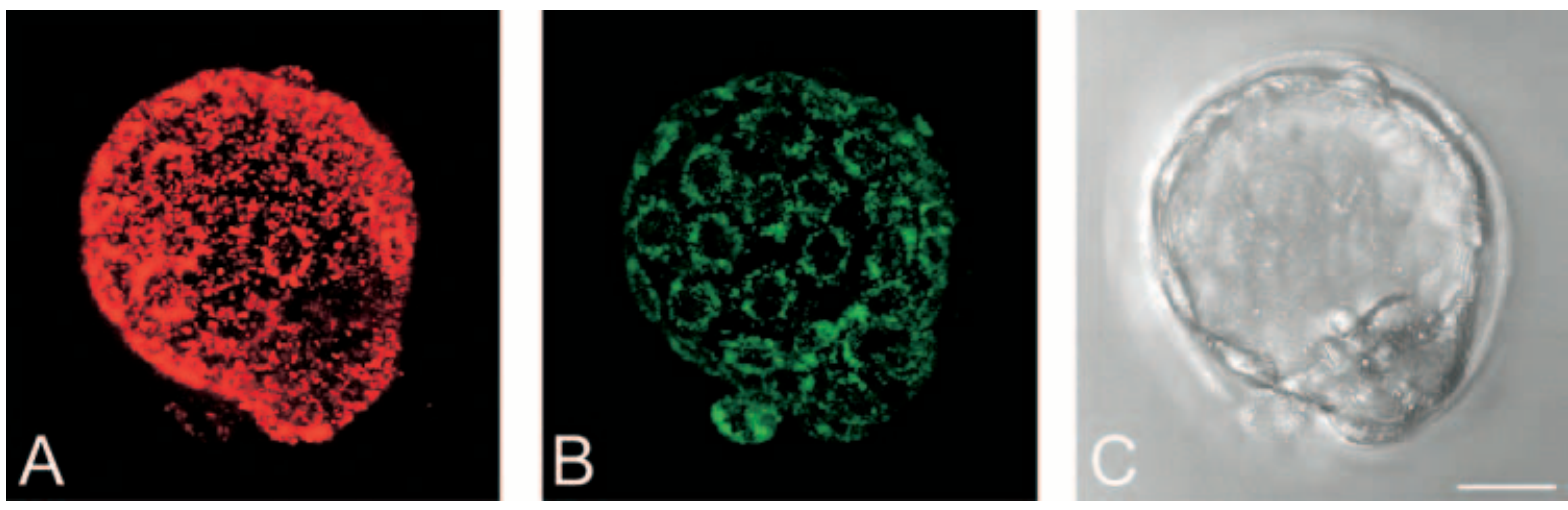

D

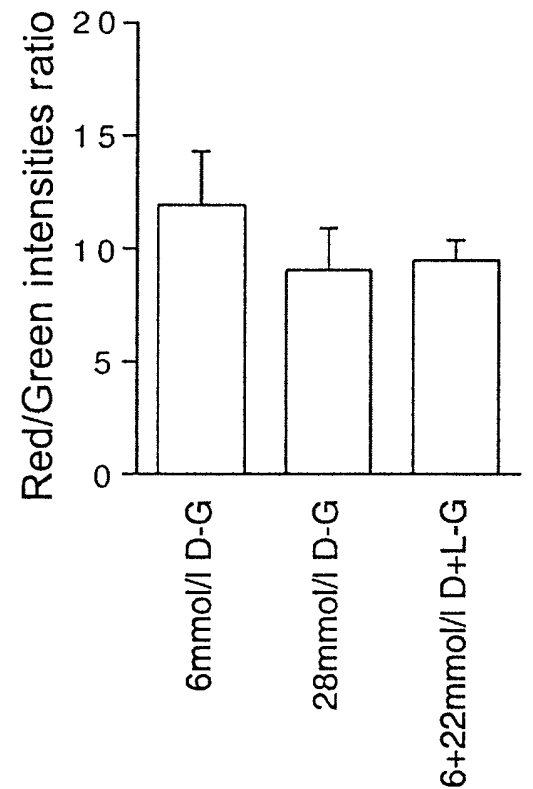

Incubation glucose concentrations

Fig. 3 (A-D). Influence of different concentrations of glucose on mitochondria distribution and mitochondrial membrane potential. Three-dimensional reconstitution by confocal laser scanning microscope of a blastocyst incubated for $24 \mathrm{~h}$ in $6 \mathrm{mmol} / \mathrm{l}$ D-glucose and stained for $\mathbf{A}$ high membrane potential and $\mathbf{B}$ low membrane potential. C Same blastocyst as in $\mathbf{A}$ and B under visible light. D Quantitative estimation of the high over low potential intensities ratio in the different experimental groups $n=8-10)$. Scale bar represents $30 \mu \mathrm{m}$

(data not shown). In early post-implantation rat embryos recovered either from diabetic or from normal females and cultured in high D-glucose concentrations, oxidative stress is regarded an essential factor in the aetiology of associated developmental anomalies [11, 12]. Direct and indirect evidence of increased intra-embryonic concentrations of ROS were found in rat post-implantation embryos when exposed to high D-glucose concentrations [25, 26]. Other data, although contradictory, showed alterations in the activity of antioxidant enzymes like superoxide dismutase and catalase as well as in the transcription of their genes in similar embryo culture systems [27, 28]. Low molecular-weight antioxidants such as Vitamin $\mathrm{E}, \mathrm{C}$ and glutathione were decreased when rat embryos were subjected to a diabetes-like environment for $28 \mathrm{~h} \mathrm{[28]} \mathrm{and} \mathrm{the} \mathrm{activity} \mathrm{and} \mathrm{gene} \mathrm{expression} \mathrm{of} \mathrm{the}$ $\gamma$-glutamylcystein synthetase, the rate-limiting GSHsynthesis enzyme, were decreased after exposure to high concentrations of glucose in vitro [25]. In preimplantation embryos, studies carried out by cyclic voltametry on mouse blastocysts cultured in serum from diabetic pregnant women showed that the viability of these embryos and the anti-oxidative power in living embryos were decreased [29]. It was then suggested that ROS were also involved in the embryotoxicity of maternal diabetes at the pre-implantation stage of development. The origin of this increased ROS generation by high D-glucose is still not clear but a substrate overload in the mitochondrial electron transport chain could induce an excessive ROS generation [12]. At the blastocyst stage, however, embryonic energy metabolism has changed from the use of pyruvate via the Krebs cycle and oxidative phosphorylation to increasing use of glucose via glycolysis to generate lactate [30]. This switch is believed to be caused by anaerobic conditions that occur at the time of implantation. In our work and in previous studies on rats [22], glucose oxidation through the Krebs cycle was minimal compared with overall glucose consumption. The oxidative stress observed in our conditions could then be induced in another way, other than by the substrate overload of the mitochondrial electron transport chain, for instance by glucose auto-oxidation, by the glycation process or by disrupting the anti-oxidative capacity. Another possibility, which could be analysed by a kinetic study, is that an initial increase in the glycolytic activity induced by the high intra-embryonic glucose concentration leads to increasing the Krebs cycle activity and the flux through the electron transport chain with the consequent generation of excessive ROS. Oxidant species could then modify the observed glucose transport and metabolism. 
A

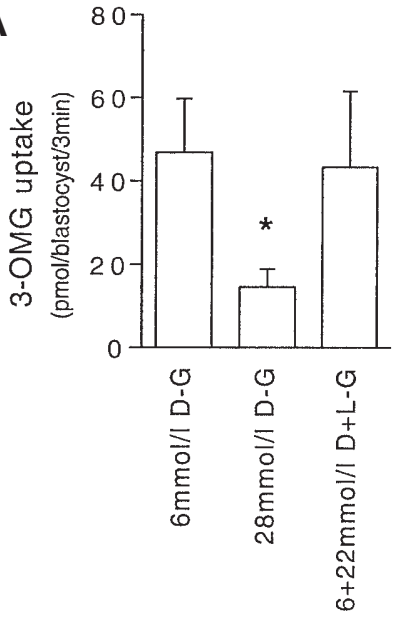

B
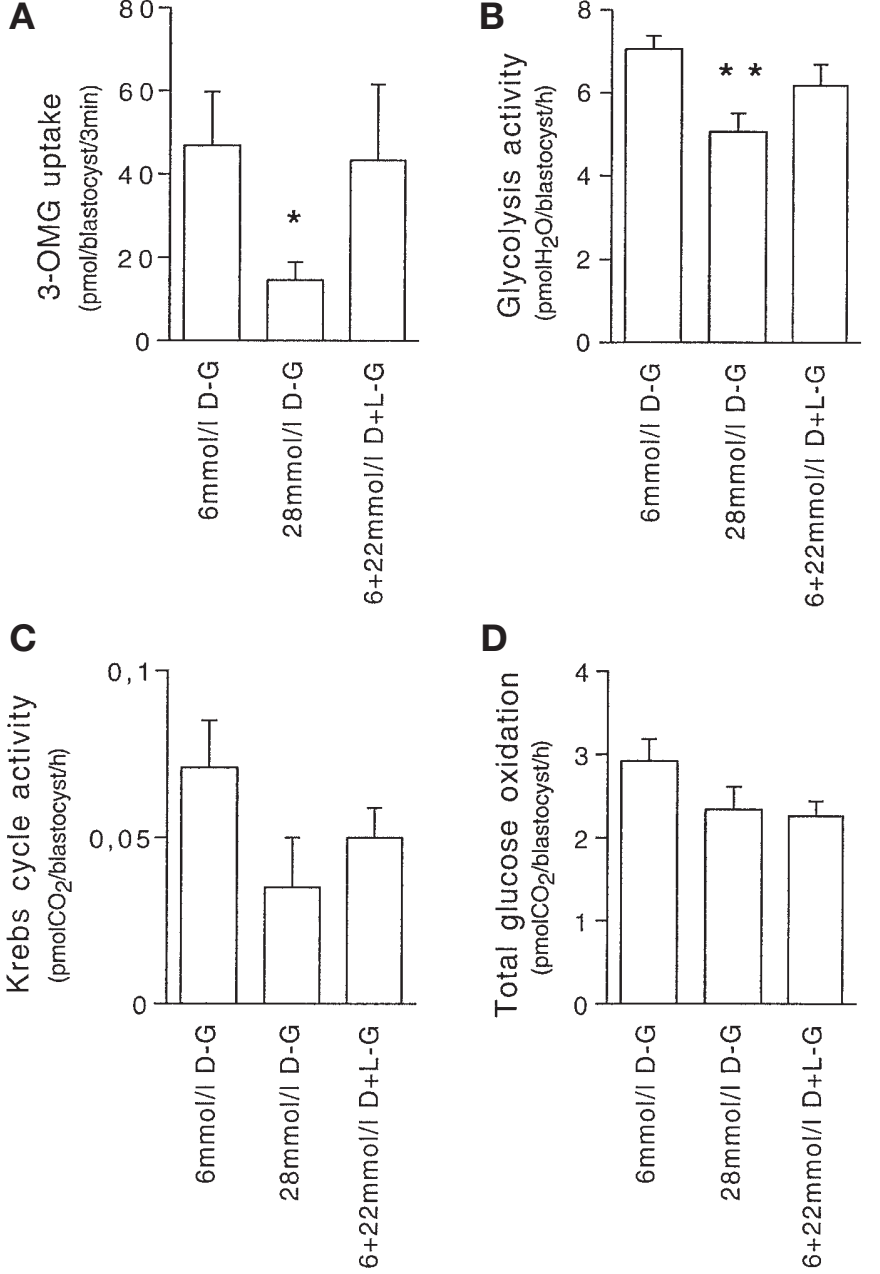

D

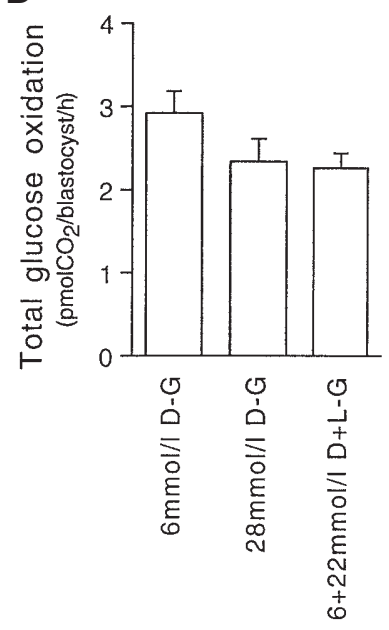

Incubation glucose concentrations

Fig. 4 (A-D). Influence of an exposure to different concentrations of glucose during $24 \mathrm{~h}$ on the main glucose metabolic pathways. A 3-O-methylglucose uptake $(n=6-9)$, $\mathbf{B}$ rate of glucose consumption by glycolysis $(n=6), \mathbf{C}$ activity of the Krebs Cycle $(n=7-8)$ and $\mathbf{D}$ rate of total glucose oxidation $(n=6-8)$ per blastocyst. * $p \leq 0.05, * * p \leq 0.01$

Excessive generation of ROS has been shown to trigger apoptosis in many cell systems. In studies on the effects of age-associated oxidative stress, it has been proposed that oxidant agents like hydrogen peroxide or the thiol-oxidation agent diamide, triggered cell cycle arrest and ultimately apoptosis in mouse zygotes and blastocysts [31, 32, 33]. A disruption of mitochondrial membrane potential has been observed in mouse zygotes after exposure to mild concentrations of hydrogen peroxide preceding cell death [33]. In our study, mouse blastocysts incubated in different D-glucose concentrations for $24 \mathrm{~h}$ and exposed to JC1 , a mitochondrial membrane potential marker, showed no change of the membrane potential or distribution of mitochondria. This confirmed at least the particular insensitivity of TE-cell lineage to the exposure to high D-glucose concentrations. Our data showed that oxidative stress and cell death occurred mainly in the ICM cell lineage of the blastocyst exposed to high D-glucose. However, we did not detect the ICM cell mitochondria, possibly because the tight junctions of the TE cells prevented JC-1 from reaching the ICM core. Another explanation could be a weak ICM mitochondrial activity. A similar observation was reported in the hamster blastocyst using the mitochondrial potential-dependent fluoroprobe rhodamine123 [34].

In our study, the exposure of mouse blastocysts to high D-glucose for $24 \mathrm{~h}$ induced a drop in glucose transport as shown by the decreased initial rate of 3OMG uptake. Mouse blastocysts depend mainly on facilitative glucose transporters for glucose supply [21] but a passive diffusion of this molecule [35] and an active transport system [36] have also been reported. Recent studies showed that the glucose transporter Glut1 protein expression and function were decreased in mouse blastocysts upon $72 \mathrm{~h}$ of high D-glucose exposure in vitro [37]. Mouse blastocysts recovered from diabetic females also showed decreased protein expressions and transcript contents of the facilitative glucose transporters GLUT1, GLUT2 and GLUT3 [14], which have been observed previously at this stage of development [38]. In mouse trophoblasts and human term placenta trophoblasts, a down-regulation of the GLUT1 mRNA and protein expressions with a concurrent drop in glucose uptake have been shown when exposed to high D-glucose concentrations [39, 40]. In addition, a recent study proposed in human term placental trophoblasts, a general auto-regulatory effect of glucose on its transport by promoting translocation of the glucose transporters from the cell surface to the intra-cellular compartment [41]. Similar protective mechanisms could possibly occur in mouse blastocysts exposed to high D-glucose concentrations because TE cells undergoing trophoblast differentiation are responsible of the extraembryonic glucose uptake in blastocysts.

We also found a decreased glycolytic activity in blastocysts after exposure to high D-glucose concentrations for $24 \mathrm{~h}$. The Krebs cycle activity was very low in all groups and was slightly decreased in high D-glucose-treated blastocysts. These results confirmed the preferential metabolism of glucose by glycolysis in mouse blastocysts [30]. The drop in the glycolytic activity when exposed to high D-glucose could result from the decreased glucose uptake in these embryos but it could also result from a specific inhibition of the glycolytic chain. This hypothesis was supported by our data on total glucose oxidation and the PPP, which were not decreased in high D-glucose-treated embryos compared with the control blastocysts, suggesting that the inhibition has occurred downstream glucose transport and the hexokinase step. The glycolysis inhibition independent from the glucose-uptake drop was also supported by the reported low glucose 
concentrations needed to saturate the glycolytic activity in rats [22] and the glucose uptake in mice [21]. In addition, free glucose intraembryonic accumulation has been shown in mouse blastocysts when embryos were exposed to high D-glucose concentrations [42]. Thus, apart from the decreased glucose uptake, enough intraembryonic substrate could have been available to sustain glucose metabolism in blastocysts after incubation in high D-glucose concentrations.

Of interest, studies on the differential metabolism of ICM and TE cells showed that ICM cells of mouse blastocysts consume threefold more glucose through glycolysis than do the TE lineage cells [43]. The observed drop in the glycolytic pathway activity could reflect mainly a decreased glucose metabolism of ICM cells. Considering that this cell lineage showed also increased ROS generation, an oxidative damage of a glycolytic enzyme could cause the inhibition of glycolytic activity. Indeed, in other cell systems, it has been shown that the glycolytic enzyme glyceraldehyde-3-phosphate dehydrogenase was inhibited by ROS [44, 45].

In conclusion, our data showed a high incidence of cell death and high ROS generation principally in the ICM cell lineage of mouse blastocysts exposed to high D-glucose for $24 \mathrm{~h}$. Decreased glycolytic pathway activity but unmodified PPP activity were also observed in these embryos. These metabolic results suggest that, apart from the observed high D-glucose-induced drop in glucose uptake, other mechanisms, possibly oxidative stress, could disturb glucose metabolism and energy production in these embryos.

Acknowledgements. This work was supported by a grant from the European Foundation for the Study of Diabetes (Fonds Suzanne et Jean Pirart), by an Action of Concerted Investigation from the General Research Direction of the French Community in Belgium (grant No. 96/01-96), by the Juvenile Diabetes Foundation International and by a Found for Scientific Medical Research of Belgium (grant No. 3.4527.99). S. Pampfer is Senior Research Associate and I. Donnay, Research Associate at the National Foundation for Scientific Research, Belgium. The authors would like to express their gratitude to I. Vanderheyden, C. Marchand, S. Cordi and P. Vandersmissen for their expert assistance and to Professor P. Courtoy for providing access to the confocal laser scanning microscope (grant 94531 94, FNRS).

\section{References}

1. Kalter H (1987) Diabetes and spontaneous abortion: a historical review. Am J Obstet Gynecol 156: 1243-1253

2. Mills JL, Knopp RH, Simpson JL et al. (1988) Lack of relation of increased malformation rate in infants of diabetic mothers to glycemic control during organogenesis. N Engl J Med 318: 671-676

3. Mills JL, Simpson JL, Driscoll SG et al. (1988) Incidence of spontaneous abortion among normal and insulin-dependent diabetic women whose pregnancies were identified within 21 days of conception. N Engl J Med 319: 1617-1623
4. Pampfer S, De Hertogh R (1996) Preimplantation embryopathy associated with maternal diabetes. Diabetes Rev 4: 90-113

5. Moley KH (1999) Diabetes and preimplantation events of embryogenesis. Semin Reprod Endocrinol 17: 137-151

6. Pampfer S (2000) Peri-implantation embryopathy induced by maternal diabetes. J Reprod Fertil Suppl 55: 129-139

7. Pampfer S (2000) Apoptosis in rodent peri-implantation embryos: differential susceptibility of inner cell mass and trophectoderm cell lineages. Placenta 21 [Suppl A]: S3-S10

8. Pampfer S, Vanderheyden I, McCracken JE, Vesela J, De Hertogh R (1997) Increased cell death in rat blastocysts exposed to maternal diabetes in utero and to high glucose or tumor necrosis factor- $\alpha$ in vitro. Development 124: 4827-4836

9. Lea RG, McCravken JE, McIntyre SS, Smith W, Baird JD (1996) Disturbed development of the preimplantation embryo in the insulin-dependent diabetic BB/E rat. Diabetes 45: $1463-1470$

10. Moley KH, Chi MM-Y, Knudson CM, Korsmeyer SJ, Mueckler MM (1988) Hyperglycemia induces apoptosis in pre-implantation embryos through cell death effector pathways. Nat Med 4: 1021-1024

11. Eriksson UJ, Borg LAH (1991) Protection by free oxygen radical scavenging enzymes against glucose-induced embryonic malformations in vitro. Diabetologia 34: 325-331

12. Eriksson UJ, Borg LAH (1993) Diabetes and embryonic malformations: role of substrate-induced free-oxygen radical production for dysmorphogenesis in cultured rat embryos. Diabetes 42: 411-419

13. Das UG, Sadiq HF, Soares MJ, Hay WW, Devaskar SU (1998) Time-dependent physiological regulation of rodent and ovine placental glucose transporter (Glut-1) protein. Am J Physiol 274: R339-R347

14. Moley KH, Chi MM-Y, Mueckler MM (1998) Maternal hyperglycemia alters glucose transport and utilization in mouse preimplantation embryos. Am J Physiol 275: E38E47

15. Nasr-Esfahani MH, Aitken JR, Johnson MH (1990) Hydrogen peroxide levels in mouse oocytes and early cleavage stage embryos developed in vitro and in vivo. Development 109: 501-507

16. Niki E (1990) Free radical initiators as source of water- or lipid-soluble peroxyl radicals. Methods Enzymol 186: 100-108

17. Viner RI, Ferrington DA, Aced GI, Miller-Schlyer M, Bigelow DJ, Schôneich C (1997) In vivo aging of rat skeletal muscle sarcoplasmic reticulum Ca-ATP-ase. Chemical analysis and quantitative simulation by exposure to low levels of peroxyl radicals. Biochim Biophys Acta 1329 : 321-335

18. Pantaleon M, Harvey MB, Pascoe WS, James DE, Kaye PL (1997) Glucose transporter Glut3 : ontogeny, targeting and role in the mouse blastocyst. Proc Natl Acad Sci USA 94: 3795-3800

19. O'Fallon JV, Wright RW (1986) Quantitative determination of the pentose phosphate pathway in preimplantation mouse embryos. Biol Reprod 34: 58-64

20. O'Fallon JV, Wright RW (1987) Calculation of the pentose phosphate and Embden-Myerhoff pathways from a single incubation with [U-14C]- and [5-3H]glucose. Anal Biochem 162: 33-38

21. Gardner DK, Leese HJ (1988) The role of glucose and pyruvate transport in regulating nutrient utilization by preimplantation mouse embryos. Development 104: 423-429

22. Dufrasnes E, Vanderheyden I, Robin D, Delcourt J, Pampfer S, De Hertogh R (1988) Glucose and pyruvate metabo- 
lism in preimplantation blastocysts from normal and diabetic rats. J Reprod Fertil 98: 169-177

23. Pampfer S, Cordi S, Vanderheyden I et al. (2001) Expression and role of Bcl-2 in rat blastocysts exposed to high Dglucose. Diabetes 50: 143-149

24. Hinck L, Van Der Smissen P, Heusterpreute M, Donnay I, De Hertogh R, Pampfer S (2001) Identification of Caspase-3 and Caspase-Activated deoxyribonuclease in rat blastocysts and their implication in the induction of chromatin degradation (but not nuclear fragmentation) by high glucose. Biol Reprod 64: 555-562

25. Trocino RA, Akazawa S, Ishibashi M et al. (1995) Significance of glutathion depletion and oxidative stress in early embryogenesis in glucose-induced rat embryo culture. Diabetes 44: 992-998

26. Wentzel P, Welsh N, Eriksson UJ (1999) Developmental damage, increased lipid peroxidation, diminished cyclooxygenase-2 gene expression, and lowered prostaglandin E2 levels in rat embryos exposed to a diabetic environment. Diabetes 48: 813-820

27. Forsberg H, Borg LAH, Cagliero E, Eriksson UJ (1996) Altered levels of scavenging enzymes in embryos subjected to a diabetic environment. Free Radic Res 24: 451-459

28. Ornoy A, Zaken V, Kohen R (1999) Role of reactive oxygen species (ROS) in the diabetes-induced anomalies in rat embryos in vitro: reduction in antioxidant enzymes and low-molecular-weight antioxidants (LMWA) may be the causative factor for increased anomalies. Teratology 60: 376-386

29. Ornoy A, Kimyagarov D, Yaffee P, Abir R, Raz I, Kohen R (1996) Role of reactive oxygen species in diabetes-induced embryotoxicity: studies on pre-implantation mouse embryos cultured in serum from diabetic pregnant women. Isr J Med Sci 32: 1066-1073

30. Martin KL, Leese HJ (1995) Role of glucose in mouse preimplantation embryo development. Mol Reprod Dev 40: 436-443

31. Liu L, Trimarchi JR, Keefe DL (1999) Thiol oxidation-induced embryonic cell death in mice is prevented by the antioxidant dithiothreitol. Biol Reprod 61: 1162-1169

32. Liu L, Trimarchi JR, Keefe DL (2000) Involvement of mitochondria in oxidative stress-induced cell death in mouse zygotes. Biol Reprod 62: 1745-1753

33. Liu L, Keefe DL (2000) Cytolpasm mediates both development and oxidation-induced apoptotic cell death in mouse zygotes. Biol Reprod 62: 1828-1834

34. Barnett DK, Kimura J, Bavister BD (1996) Translocation of active mitochondria during hamster preimplantation embryo development studied by confocal laser scanning microscopy. Dev Dyn 205: 64-72

35. Gardner HG, Kaye PL (1995) Characterization of glucose transport in preimplantation mouse embryos. Reprod Fertil Dev 7: 41-50

36. Chi MMY, Manchester JK, Basuray R et al. (1993)An unsual active hexose transport system in human and mouse preimplantation embryos. Proc Natl Acad Sci USA 90: 10023-10025

37. Chi MM-Y, Pingsterhaus J, Carayannopoulos M, Moley KH (2000) Decreased glucose transporter expression triggers Bax-dependent apoptosis in the murine blastocyst. J Biol Chem 275: 40252-74025

38. Pantaleon M, Kaye PL (1998) Glucose transporters in preimplantation development. Rev Reprod 3: 77-81

39. Hahn T, Barth S, Weiss U, Mosgoeller W, Desoye G (1998) Sustained hyperglycemia in vitro down-regulates the Glut1 glucose transport system of cultured human term placenta trophoblast: a mechanism to protect fetal development? Faseb J 12: 1221-1231

40. Ogura K, Sakata M, Yamaguchi M, Kurachi H, Murata Y (1999) High concentration of glucose decreases glucose transporter- 1 expression in mouse placenta in vitro and in vivo. J Endocrinol 160: 443-452

41. Hahn T, Hahn D, Blaschitz A, Korgun ET, Desoye G,Dohr G (2000) Hyperglycemia-induced subcellular redistribution of GLUT1 glucose transporters in cultured human term placental trophoblast cells. Diabetologia 43: 173-180

42. Moley KH, Chi MM-Y, Manchester JK, McDougal DB, Lowry OH (1996) Alterations of intraembryonic metabolites in preimplantation mouse embryos exposed to elevated concentrations of glucose: a metabolic explanation for the developmental retardation seen in preimplantation embryos from diabetic animals. Biol Reprod 54: 1209-1216

43. Hewitson LC, Leese HJ (1993) Energy metabolism of the trophectoderm and the inner cell mass of the mouse blastocyst. J Exp Zool 267: 337-343

44. Hyslop PA, Hinshaw DB, Halsey WA et al. (1985) Mechanisms of antioxidant-mediated cell injury. The glycolytic and mitochondrial pathways of ADP ribosylation are major intracellular targets inactivated by hydrogen peroxide. J Biol Chem 263: 1665-1675

45. Knight RJ, Kofoed KF, Schelbert HR, Buxton DB (1996) Inhibition of glyceraldehyde-3-phosphate dehydrogenase in post-ischemic myocardium. Cardiovasc Res 32: 1016-1023 